\title{
Diurnal variations of saltation activity at Tazhong: the hinterland of Taklimakan Desert
}

\author{
Xinghua Yang $\cdot$ Qing He $\cdot$ Ali Mamtimin $\cdot$ \\ Wen Huo $\cdot$ Xinchun Liu
}

Received: 20 December 2011/Accepted: 14 November 2012/Published online: 1 December 2012

(C) The Author(s) 2012. This article is published with open access at Springerlink.com

\begin{abstract}
The Taklimakan Desert of China is a region of frequent sandstorms and, thus, is a major sand and dust source area. Tazhong, a small mining village, is located near the center of the Taklimakan Desert at a distance of $220 \mathrm{~km}$ from the desert margins. Near Tazhong, we conducted a 2-year field investigation designed to monitor the diurnal variation of saltation activity using fast-responding piezoelectric saltation sensors (Sensits). Results suggest that saltation activity tends to occur more frequently during daytime in all seasons, relatively high levels of saltation activity are maintained from around 11:30 to around 16:30 local standard time (LST), because of stronger wind speed, higher soil temperature and lower relative humidity. During the spring and summer seasons, the saltation activity can occur at any time of the day, while there are some periods with zero saltation seconds at night and in the early morning during autumn and winter seasons. The results confirm that sandstorms tend to occur more frequently during daylight hours, so it may be helpful to forecast and guard against the occurrence of blowing sand or sandstorms in the Taklimakan Desert.
\end{abstract}

Keywords Aeolian sand transport - Saltation activity · Diurnal variation $\cdot$ Sensit . The Taklimakan Desert

Responsible editor: J. Fasullo.

X. Yang $\cdot$ Q. He $(\bowtie) \cdot$ A. Mamtimin $\cdot$ W. Huo $~ X$ X. Liu Institute of Desert Meteorology, China Meteorological Administration, No. 46, Jianguo Road, Urumqi 830002, Xinjiang, China

e-mail: qinghe@idm.cn

X. Yang $\cdot$ Q. He · A. Mamtimin · W. Huo · X. Liu Desert Atmosphere and Environment Observation Experiment of Taklimakan Station, Tazhong 841000, China

\section{Introduction}

Aeolian sand transport is a serious problem in many arid regions in the world, and it is considered to be the significant part of global biogeochemical cycles (Liu 2009; McTainsh and Strong 2007). Saltation plays a key role in aeolian sand transport studies because saltating grains account for about 50-75\% of the total aeolian transport (Bagnold 1941; Chepil 1945). Much research work on saltation has been carried out including field experiments (Bagnold 1941; Chepil 1945; Douglas et al. 2011; Gillette and Walker 1977; Stout 2003; Yang et al. 2012), wind tunnel experiments (Dong et al. 2006; Remigius 2003; Van Pelt et al. 2006), theoretical analyses (Bauer et al. 1998) and numerical simulations (Jasper and Nilton 2009; Shao 2008; Van Boxel et al. 1999; Zheng et al. 2003).

Many researches indicate that atmospheric conditions are important environmental controls of aeolian sand transport. For example, wind speed is an important dynamic factor of aeolian sand transport, and the erosion process occurs only when the wind speed exceeds the threshold velocity (Bagnold 1941). Temperature, atmospheric moisture and soil moisture are other important impact factors of aeolian sand transport. Dust storms are observed to easily occur in winter on the Canadian prairies, and particularly in early spring, as frost action pulverizes the soil clods (Wheaton and Chakravarti 1990), and the aeolian transport more easily occurs in cold deserts because of the aerodynamic drag required to entrain sand sized particles can be $30 \%$ lower in cold settings, as compared to hot deserts (McKenna Neuman 2003). Atmospheric moisture and soil moisture can influence the aeolian sand transport through changing the threshold velocity, but the relationships are complex, because the threshold velocity does not always decrease with increasing atmospheric moisture or soil 
moisture (Ravi et al. 2004; Ravi and D'Odorico 2005; McKenna Neuman and Sanderson 2008; Sankey et al. 2009). Stout (2010) has observed that sand movement occurs more frequently during the day because of strong winds, low humidity, and a sun-dried sand surface with the lowest possible threshold velocity. In all, the atmospheric conditions, such as atmospheric moisture, soil moisture and atmospheric temperature, acting independently or dependently as controls on aeolian sand transport through the following physical processes: (1) The effect of atmospheric viscosity and density on the fluid drag force acting to dislodge sand particles; (2) the effect of viscosity on the turbulent wake shed from these particles, and the frequency and magnitude of burst-sweep events and; (3) the variations of inter-particle cohesion via adsorbed water (McKenna Neuman 2003).

The objective of this study is to analyze the diurnal variations of saltation activity in different seasons and its influencing factors, such as wind speed, surface temperature, soil moisture and relative humidity based on 2 years of measurement of active aeolian processes at Tazhong, the hinterland of the Taklimakan Desert.

\section{Methods}

\subsection{Physical setting}

The Taklimakan Desert, located in the central part of the Tarim Basin in the Uygur Autonomous Region of Xinjiang, northwestern China (Fig. 1), is the second largest shifting sand desert in the world with about $85 \%$ of its environment made up of shifting sand dunes (Sun and Liu 2006). It is known as an important sand and dust source area and a high incidence area of sandstorms in China (Qian et al. 2002;

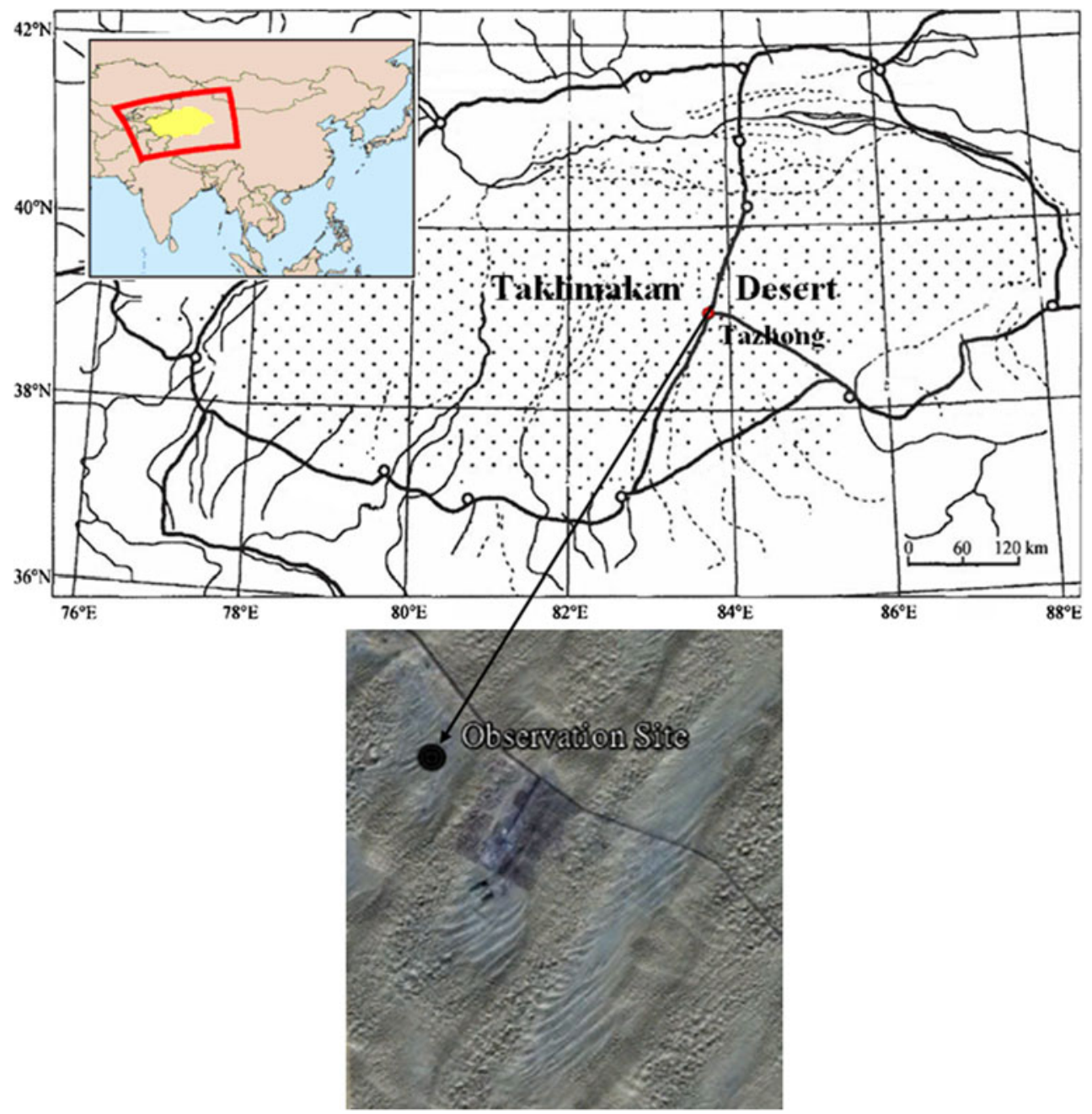

Fig. 1 Location of the Taklimakan Desert within the Tarim Basin. Tazhong is located on the center of the Taklimakan Desert. The inset shows the location of the Tarim Basin (yellow area) within Asia. In the satellite photograph, the black dot is the location of the observation site. The satellite photograph shows that Tazhong area is mainly covered by longitudinal dunes, the observation site is located on a flat sandy land between two longitudinal dunes 
Wang et al. 2000; Zhou et al. 2002). The sandstorms, primarily a product of wind erosion in this region, have greatly influenced climatic change in East Asia (Zhao et al. 2006). Sand encroachment associated with sandstorms has also damaged oases within the Taklimakan Desert.

Tazhong has a linear distance of $220 \mathrm{~km}$ to the desert edge. There is almost no vegetation and the climate is very dry with a precipitation of $25.0 \mathrm{~mm}$ per year. The average number of days of sandstorms and blowing sand in any given year is about 100 days annually (Wang et al. 2003).

The observation site chosen for this study is a flat sandy area, consisting of shifting sand surface. Laboratory test results show that the Sensit-H11LIN could not respond to suspended fine dust (less than $50 \mu \mathrm{m}$ ) (Sensit Company 2007), so 21 samples of surface sand (including dune sand, flat sandy land sand) were obtained from the site and its surrounding area, and measured to obtain the grain size distribution. The results showed that these sands are mainly 'fine sand' and 'very fine sand' with an average grain size of $147 \mu \mathrm{m}$. About $0.3 \%$ of the grains are smaller than $50 \mu \mathrm{m}$ and only $7.6 \%$ have grains greater than $250 \mu \mathrm{m}$.

\subsection{Monitoring methods}

The measurements were taken during 24 months, from 1 September 2008 to 31 August 2010. A measurement system was installed on the observation site which consisted of a 2-m tall meteorological tower, a piezoelectric saltation sensor (Sensit) and a data collector (CR1000 Campbell) (Fig. 2). Wind speed was measured with WAA151 anemometers (Vaisala) mounted at the heights of 5, 10, 20, 50, 100 , and $200 \mathrm{~cm}$. Instrument for measuring relative humidity and air temperature (HMP45D Vaisala) was mounted at a height of $1.5 \mathrm{~m}$ above the surface. Soil temperature measuring instrument (109 Campbell) was mounted at a height of $0 \mathrm{~cm}$ above the surface. Soil moisture instrument (CS616 Campbell) was mounted at a depth of $2.5 \mathrm{~cm}$ below the surface. All meteorological variables were measured at a frequency of $1 \mathrm{~Hz}$ and averaged every $5 \mathrm{~min}$.

Saltation activity was monitored with piezoelectric saltation sensor (Sensit). The Sensit is designed to produce a pulse signal each time the transducer is impacted by a saltating sand particle. During periods of active saltation, the piezoelectric transducer produced a signal that was used simply as an on-or-off indicator of saltation activity. Each pulse signal generated by each particle impact was detected and if one or more impacts were detected during a given second then that second was registered as one 'saltation second' (Stout 2003). At the end of each 5-min period, the total number of saltation seconds was summed and recorded in the data collector. The transducers of the Sensit were located $5 \mathrm{~cm}$ above the surface.

In this study, the total number of saltation seconds was summed for a given 'time of day' for autumn, winter, spring, summer, and all days by summing all saltation

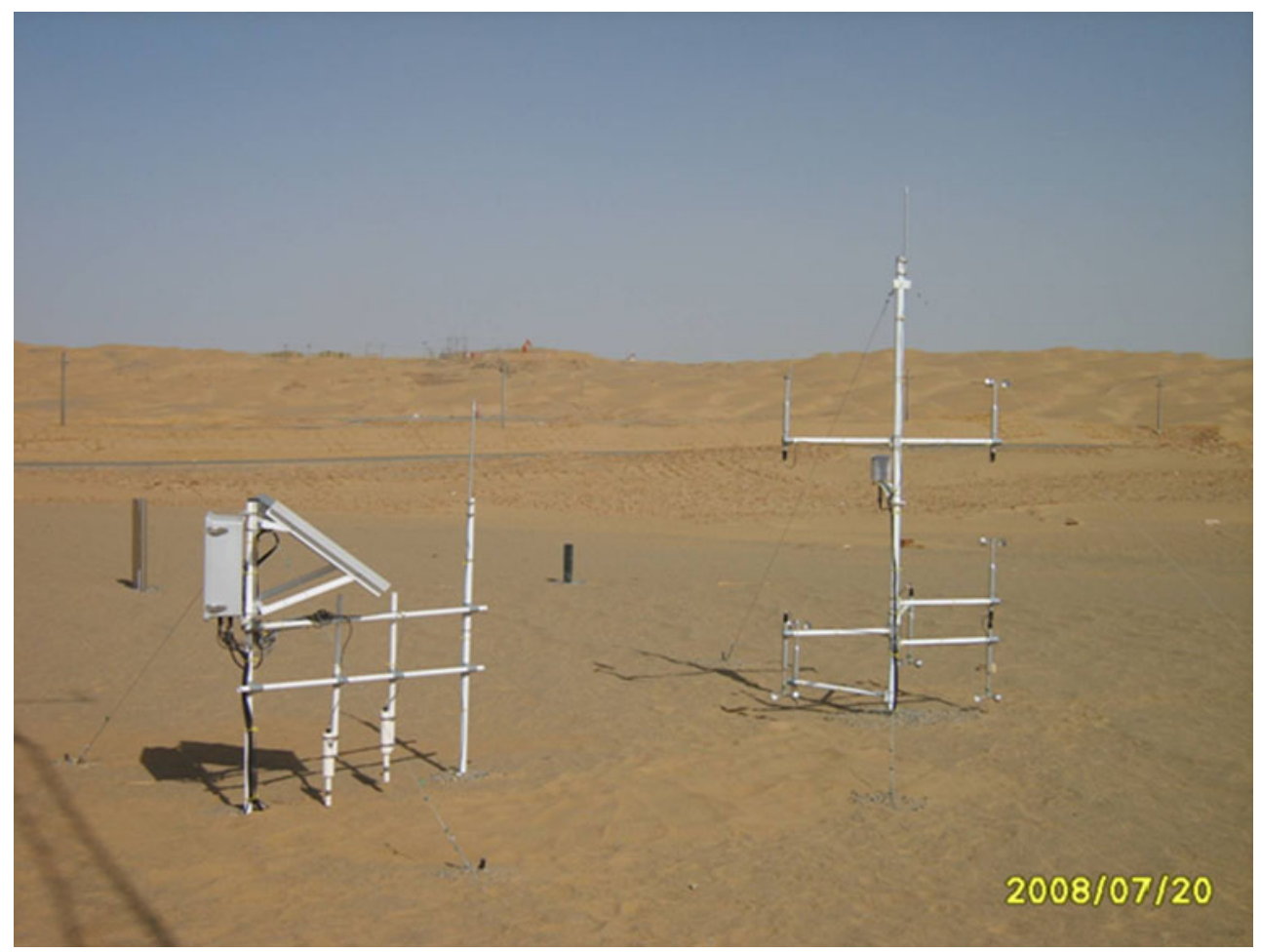

Fig. 2 Photograph of the 2-m meteorological tower and piezoelectric saltation sensor (Sensit) 
seconds of every 5-min period for the entire measurement period. The values of wind speed, surface temperature, soil moisture and relative humidity were averaged for a given 'time of day' in the same way that the saltation seconds were summed. The peak values and its appearing time, peak zones (more than average value), standard deviation, skewness and kurtosis of the diurnal distributions of saltation seconds in different seasons were computed so as to compare the distributions quantitatively.

Following Stout (2004), the critical threshold wind velocity was computed using the following equation:

$u_{t}=\bar{u}-\sigma \cdot \Phi^{-1}(\gamma)$,

where $u_{t}$ is the critical threshold wind velocity, $\bar{u}$ is the average wind velocity per minute, $\sigma$ is the standard deviation of wind velocity per minute, $\gamma$ is the intensity of saltation activity which is higher than zero and less than one. When $\gamma=1$, it indicates continuous occurrence of saltation during observation; when $\gamma=0$, there is no saltation activity occurring; $\Phi^{-1}$ is the inverse of normal distribution function of $\gamma$. Critical threshold was determined at 5-min intervals for saltation activity values between 0.02 and 0.98 (Stout 2004).

\section{Results and discussion}

\subsection{Diurnal variations of saltation activity}

Figure 3 shows the diurnal distribution of saltation seconds of all days. It can be found that the shape of the distribution curve is an unstandard bell-shaped with some fluctuations, indicating that more saltation activity would occur during daytime. The data show that $83 \%$ of the total saltation seconds occur during daytime (08:00-20:00 LST), and

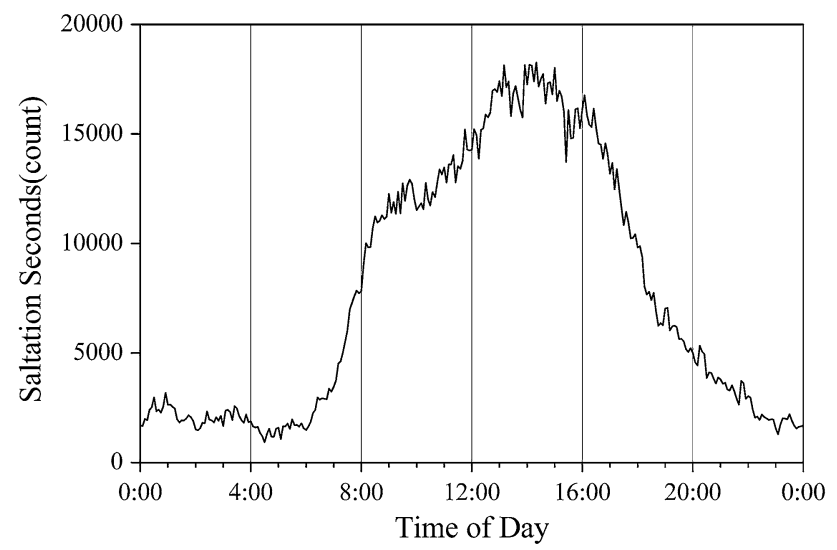

Fig. 3 Diurnal distribution of the saltation seconds measured over 24 months from 1 September 2008 to 31 August 2010. Values represent the total number of saltation seconds for a given 5-min interval that defines the 'time of day' only $17 \%$ of the saltation seconds occur at night and early morning (20:00-08:00 LST). The lowest values of saltation seconds appear at the early morning period between 04:00 and 05:00 LST, with a minimum appearing at 04:30 LST. After 06:00 LST, there is a rapid rise in saltation seconds, especially from 07:00 to 09:00 LST. Relatively high levels of saltation activity are maintained from 11:30 to 17:30 LST with peak value appearing at 14:20 LST. After that, a rapid decrease in saltation seconds occurs and reaches a low point at night at 23:05 LST.

The diurnal distribution of saltation activity at Tazhong is similar to the research result of high plains of the Llano Estacado by Stout (2010), but there are some distinct differences between them. These differences include the time of the lowest values, peak values, the rapid rise and decrease in saltation activity. In particular, the curve of rising and decreasing parts is steeper in the high plains of the Llano Estacado. These differences reflect the influence of different natural environmental conditions on saltation activities. For example, the high plains of the Llano Estacado are in a semi-arid region in North America, whereas Tazhong of the Taklamakan Desert is in arid or very arid region in Central Asia. The high plains are located at $32^{\circ} \mathrm{N}$ latitude whereas Tazhong is located at $39^{\circ} \mathrm{N}$ latitude. The environmental differences include vegetation cover, topography and geomorphology, soil composition, and atmospheric conditions such as soil moisture, atmospheric moisture, atmospheric temperature and wind speed. These are important influencing factors of aeolian sand transport (Allgaier 2008; Shi and Huang 2010; Chen et al. 1996; Cornelis 2006; Davidson-Arnott et al. 2008; Fecan et al. 1999; McKenna Neuman 2003; McKenna Neuman and Langston 2006; McKenna Neuman and Sanderson 2008; Ravi et al. 2004; Ravi and D'Odorico 2005; Sankey et al. 2009; Wiggs et al. 2004). In addition, it is well known that the length of the day can vary more widely during summer at high latitudes, so the span of bell-shaped distribution curve of saltation seconds at Tazhong is wider than that of the high plains.

Figure 4 shows the diurnal distributions of the saltation seconds during autumn, winter, spring and summer seasons. Overall, the diurnal distributions of the seasons are similar to all days, the shape of the distribution curves are unstandard bell-shaped too. However, some differences among seasons can be found upon close inspection; some statistical parameters are shown in Table 1 . The peak values are $2,777,928,8,924,7,435 \mathrm{~s}$, respectively, during autumn, winter, summer and spring, and appear, respectively, at 13:55, 14:35, 15:00 and 14:05 LST. Peak zones (more than average value) of saltation activity are maintained between 8:20-18:05, 9:25-16:45, 8:15-18:50, and 7:35-18:10 LST, respectively. Compared to spring and summer, the start of peak zones appears later and ends 
Fig. 4 Comparison of the diurnal distributions of saltation seconds with the diurnal distributions of mean 5-min wind speed at $2 \mathrm{~m}$ heights
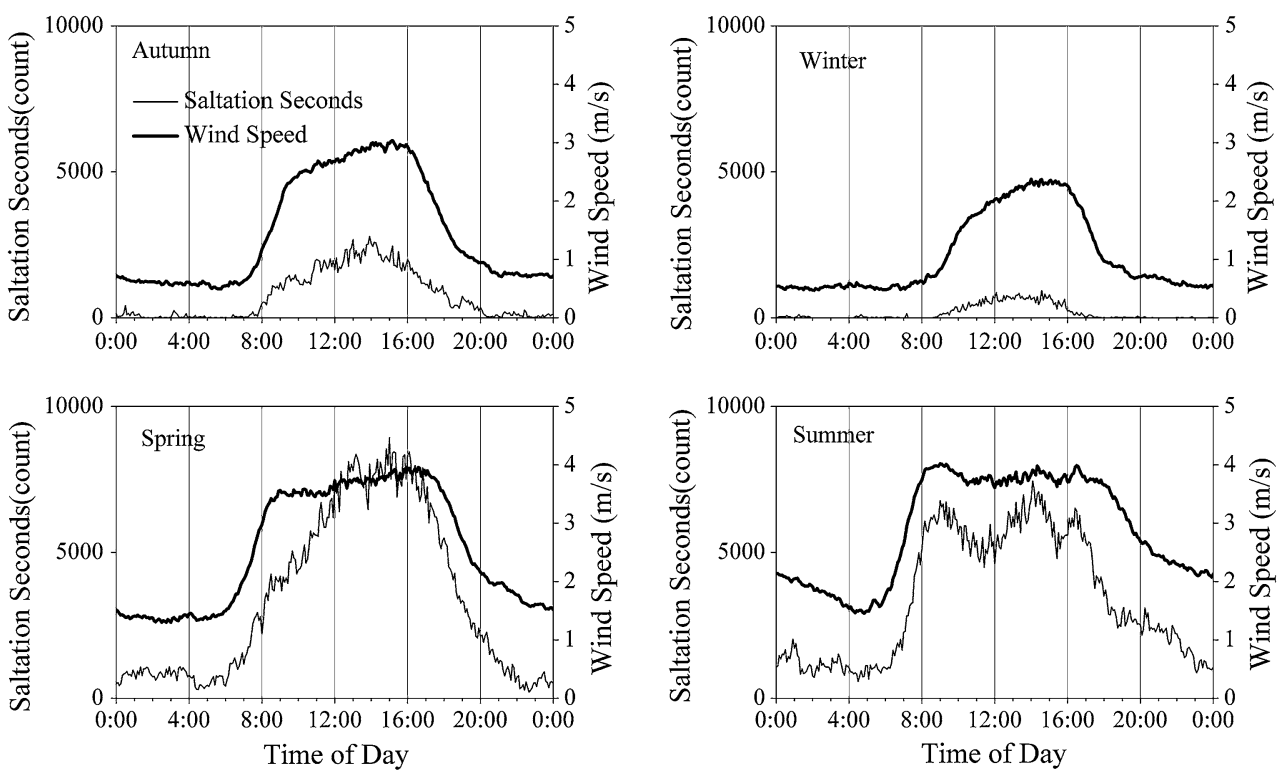

Table 1 Parametric statistics of diurnal distribution of saltation seconds in different seasons

\begin{tabular}{lcllllr}
\hline Seasons & \multicolumn{6}{l}{ Diurnal distribution of saltation seconds (s) } \\
\cline { 2 - 7 } & $\begin{array}{l}\text { Peak } \\
\text { values }\end{array}$ & $\begin{array}{l}\text { Appearing } \\
\text { time }\end{array}$ & $\begin{array}{l}\text { Peak zone (more } \\
\text { than average value) }\end{array}$ & $\begin{array}{l}\text { Standard } \\
\text { deviation }\end{array}$ & Skewness & Kurtosis \\
\hline Atumun & 2,777 & $13: 55$ & $8: 20-18: 05$ & 827.3 & 0.75 & -0.88 \\
Winter & 928 & $14: 35$ & $9: 25-16: 45$ & 256.1 & 1.33 & 0.23 \\
Spring & 8,924 & $15: 00$ & $8: 15-18: 50$ & $2,819.4$ & 0.47 & -1.35 \\
Summer & 7,435 & $14: 05$ & $7: 35-18: 10$ & $2,130.9$ & 0.22 & -1.57 \\
\hline
\end{tabular}

earlier during autumn and winter, and is particularly more pronounced during winter. Therefore, the duration of peak zones of saltation activity is shorter during autumn and winter. The standard deviation is 2,819.4 for spring, 2,130.9 for summer, 827.3 for autumn, and 256.1 for winter, indicating that the data distribution during spring is most discrete. Results show that the values of skewness are $0.75,1.33,0.47$ and 0.22 , respectively, in autumn, winter, summer and spring, indicating that all the diurnal distribution of saltation seconds is negatively skewed, while the distribution in summer is closest to normal distribution. The values of kurtosis are $-0.88,0.23,-1.35$ and -1.57 , respectively, in autumn, winter, summer and spring, indicating that the curves of diurnal distribution of saltation seconds are more flat than normal distribution, and the curve of winter is most steep in all seasons.

There is no period with zero saltation seconds during spring and summer, indicating that saltation activity could occur at any time including at night and early morning, while there are some periods with zero saltation seconds during autumn and winter. During winter, the periods with zero saltation seconds account for $22.9 \%$ of the time of day, the periods with zero saltation seconds mainly appear at night and in the early morning, and even in the evening.

\subsection{Climatic factors}

Figure 4 shows the diurnal distributions of wind speed and saltation seconds. Generally, we found relatively strong winds during the day and lighter winds at night during all seasons, which is similar to the distributions of saltation seconds. Especially during summer, the curve of wind speed is roughly in full accord with saltation seconds, which shows that wind speed plays a key role in the saltation activity.

Interestingly, compared to spring and summer, the rapid rise in wind speed appears later and the rapid decrease appears earlier in autumn and winter. This is similar to the result reported by Stout (2010), the initial rapid increase in saltation activity tends to lag the morning rise in wind speed by about $30 \mathrm{~min}$ to an hour and the decrease in saltation activity tends to forge ahead downward wind speed in the afternoon. The lag is most likely caused by the fact that wind speed must first rise to a point where it exceeds the critical threshold of the surface before sand movement will occur. Due to this threshold effect, a time lag occurs between the initial increase of wind speed and saltation activity (Stout 2010).

Figure 5 shows the diurnal distributions of surface temperature and saltation seconds. The peak values of 
Fig. 5 Comparison of the diurnal distributions of saltation seconds with the diurnal distributions of mean 5-min surface temperature. Here, the surface temperature is soil surface temperature
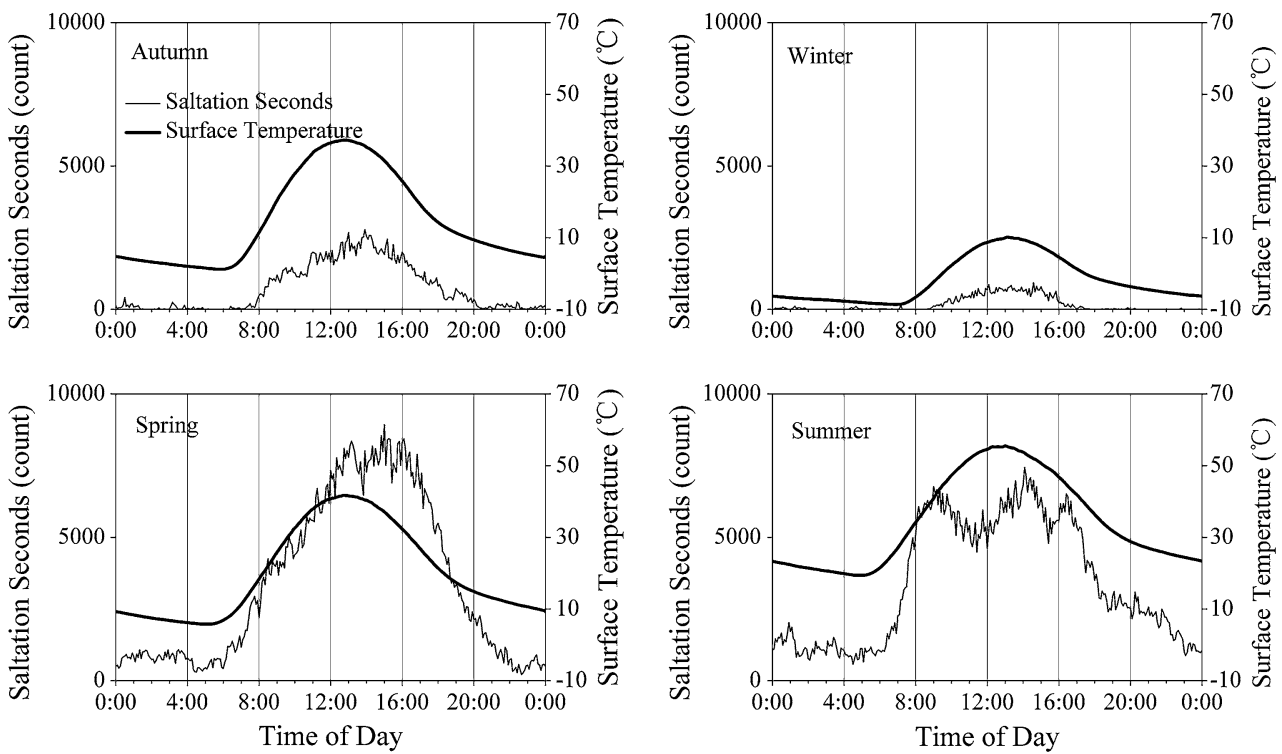

surface temperature appear between 12:40 LST and 13:20 LST, which tends to coincide with the peak values of saltation seconds. We know that the thermodynamics and dynamic factors are the main causes of saltation activity. The changes in surface temperature can impact the heat exchange between the surface and atmosphere, and strong heat exchange between the surface and atmosphere aids the occurrence of saltation activity. Generally, the temperature difference is higher between surface temperature and atmosphere temperature during the daytime, allowing for a stronger heat exchange than other times, and triggering saltation activity. The strongest heat exchange between the surface and atmosphere would occur when the surface temperature reaches its peak, so the peak values of saltation seconds follow later than that of surface temperature.
Surface moisture can influence the critical threshold, which, in turn, influences saltation activity (Wiggs et al. 2004). Stout (2007) found that the critical threshold of a sand surface may be slightly higher in the early morning due to surface moisture or dew. In this study, we measured the soil moisture of $2.5 \mathrm{~cm}$ below the surface because the surface of measurement site was covered by shifting sand, which made direct measure of surface moisture impossible. Figure 6 shows the diurnal distributions of soil moisture and saltation seconds of the measurement period. It is interesting to note that the diurnal distribution of saltation seconds is consistent with the diurnal distribution of soil moisture; relatively high soil moisture appears during the day and lower soil moisture appears at night. This may be due to moisture transfer, as a result of evaporation, from
Fig. 6 Comparison of the diurnal distribution of saltation seconds with the diurnal distribution of mean 5-min soil moisture. Here, the values of soil moisture are volume fraction, and the measurement depth is $2.5 \mathrm{~cm}$
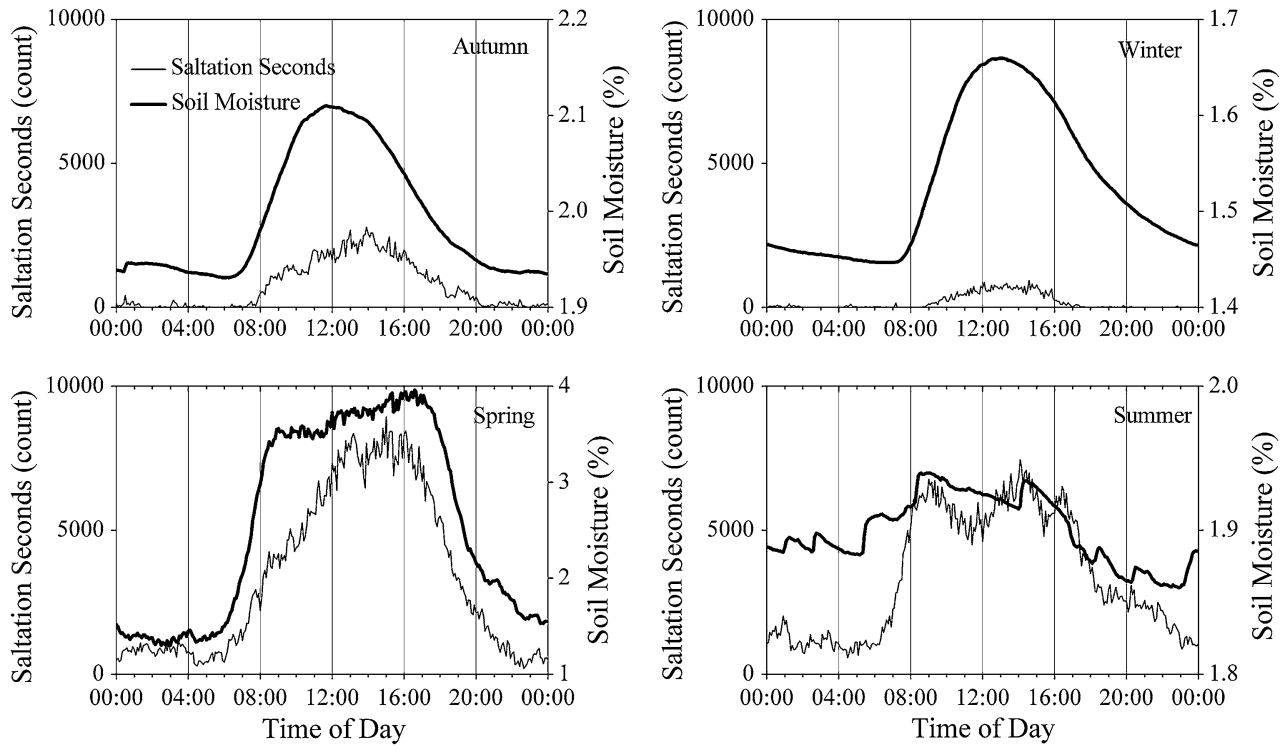

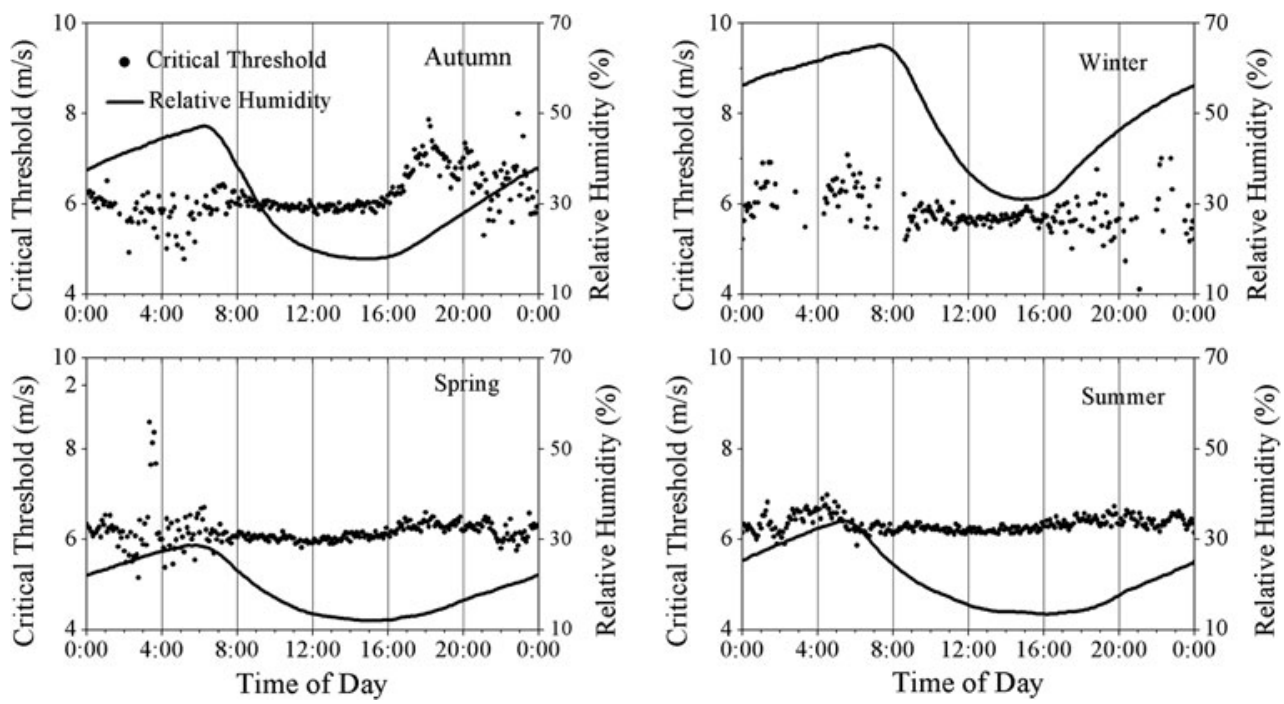

Fig. 7 Measurements of relative humidity $(1.5 \mathrm{~m})$ and critical threshold $(2 \mathrm{~m})$ obtained over a 24-h period during all seasons

Fig. 8 Comparison of the diurnal distributions of saltation seconds with the diurnal distributions of mean 5-min relative humidity mounted at a height of $1.5 \mathrm{~m}$ above the surface
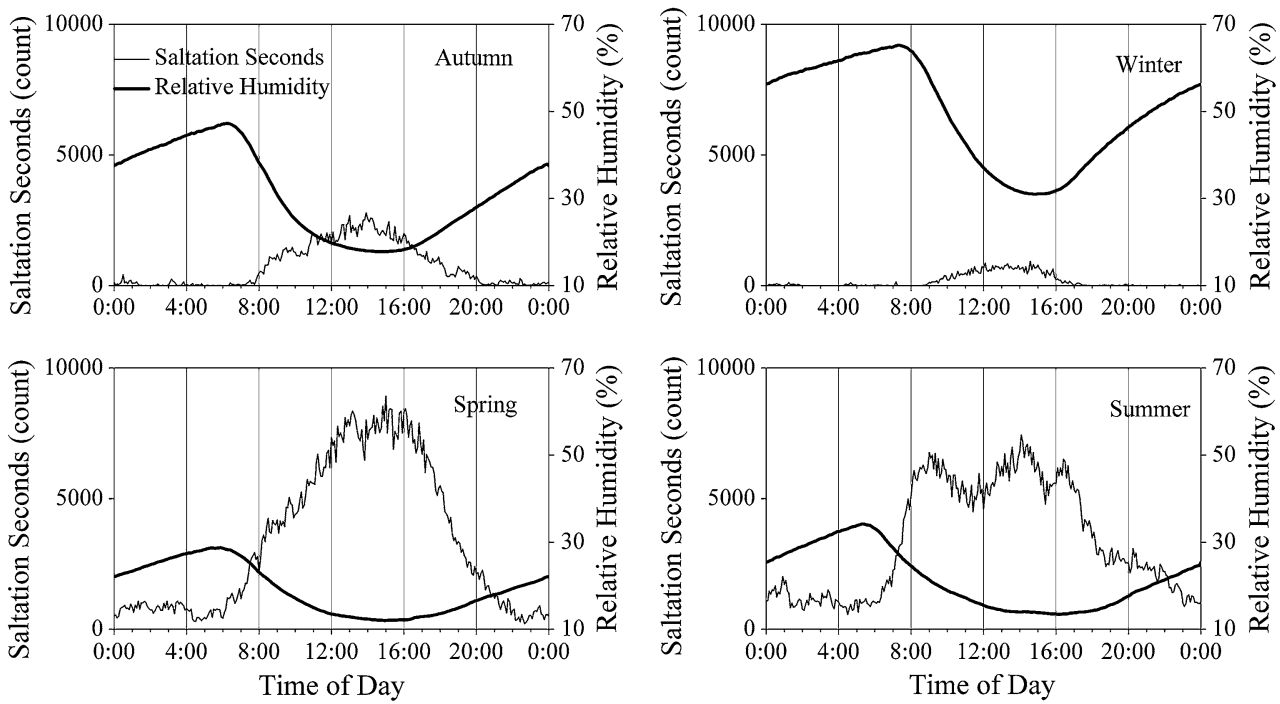

the deeper layer of soil to the top layer, causing high surface soil moisture during the day. It is necessary to measure the surface moisture in the next study.

With respect to relative humidity, research shows that threshold wind speed depends significantly on air humidity because of the variations of inter-particle cohesion via adsorbed water (McKenna Neuman 2003; McKenna Neuman and Sanderson 2008; Ravi et al. 2004; Ravi and D'Odorico 2005; Sankey et al. 2009). In this study, the critical thresholds of four seasons are calculated with the method following Stout (2004). During all seasons (Fig. 7), the critical thresholds are higher in the morning and evening (when the relative humidity is higher), and lower between 10:00 and 16:00 during autumn, spring and summer, and between 11:00 and 15:00 during winter (when the relative humidity is lower), which is consistent with the results reported by Stout (2007).

Figure 8 shows the diurnal distributions of relative humidity and saltation seconds. The relative humidity is higher between 6:00 and 9:00 LST in autumn and winter, and between 05:00 and 08:00 LST in spring and summer, this indicates that the critical thresholds are higher during these time. After that, the relative humidity decreases rapidly, resulting in a lower critical threshold. This allows the sand to respond more directly to rising wind speeds.

Overall, favorable climatic conditions are helpful to the occurrence of saltation activity. High level saltation activity occurs during the daytime, with the stronger wind speed, higher surface temperature and lower relative humidity. 


\section{Conclusion}

A 2-year continuous monitoring of saltation activity was completed using piezoelectric saltation sensors (Sensit) on a flat sandy surface of Tazhong. The diurnal variations in saltation seconds were recorded in detail. The results of diurnal variations in saltation seconds are consistent with the diurnal variations of wind speed, surface temperature and relative humidity. This indicates that the Sensit is better suited to monitor the aeolian activity in the Taklimakan Desert.

Overall, the diurnal variations in saltation activity tend to be uniform in different seasons, which is to say that saltation activities occur more frequently during the daytime and less frequently at night. The differences in diurnal variations in saltation activity in different seasons may reflect the differences in climatic factors and natural environments.

Climatic conditions have been shown to be important environmental controls for saltation activity (Chen et al. 1996; McKenna Neuman 2003; McKenna Neuman and Sanderson 2008; Ravi et al. 2004; Ravi and D'Odorico 2005; Sankey et al. 2009). In this study, favorable climatic conditions, such as stronger wind speed, higher soil temperature and lower relative humidity, aid in the occurrence of saltation activity. In an arid region as Tazhong, wind plays a main role in saltation activity, as illustrated in Fig. 4, especially the variations reported during the summer.

Acknowledgments The author would like to thank Editor John T. Fasullo and reviewers for their careful reviews of this manuscript. I would also like to thank Professor Sanjay K. Nepal of University of Waterloo for his work on language of this manuscript. This research was funded by National Natural Science Foundation of China (41175017 and 41175140), Central Scientific Research Institute of the public basic scientific research business professional (IDM201103), and China Special Fund for Meteorological Research in the Public Interest (GYHY 201006012).

Open Access This article is distributed under the terms of the Creative Commons Attribution License which permits any use, distribution, and reproduction in any medium, provided the original author(s) and the source are credited.

\section{References}

Allgaier A (2008) Aeolian sand transport and vegetation cover. Arid Dune Ecosyst Ecol Stud. doi:10.1007/978-3-540-75498-5_15

Bagnold RA (1941) The physics of blown sand and desert dunes. Methuen and Co, London

Bauer BO, Yi JY, Namikas SL et al (1998) Event detection and conditional averaging in unsteady aeolian systems. J Arid Environ 39:345-375

Chen WN, Dong ZB, Li ZS et al (1996) Wind tunnel test of the influence of moisture on the erodibility of loessial sandy loam soils by wind. J Arid Environ 34:391-402
Chepil WS (1945) Dynamics of wind erosion: I. Nature of movement of soil by wind. Soil Sci 60:305-320

Cornelis WM (2006) Hydroclimatology of wind erosion in arid and semiarid environments. In: D'Odorico P, Porporato A (eds) Dryland ecohydrology. Springer, The Netherlands, pp 141-159

Davidson-Arnott RG, Yang YQ, Ollerhead J et al (2008) The effects of surface moisture on aeolian sediment transport threshold and mass flux on a beach. Earth Surf Proc Land 33:55-74

Dong ZB, Qian GQ, Luo WY et al (2006) Analysis of the mass flux profiles of an Aeolian saltating cloud. J Geophys Res. doi: 10.1029/2005JD006630

Douglas J, Sherman LiBL et al (2011) Measuring aeolian saltation: a comparison of sensors. J Coast Res 10059:280-290

Fecan F, Marticorena B, Bergametti G (1999) Parameterization of the increase of the aeolian erosion threshold wind friction velocity due to soil moisture for arid and semi-arid areas. Ann Geophys 17:149-157

Gillette DA, Walker TR (1977) Characteristics of airborne particles produced by wind erosion of sandy soil, high plains of west Texas. Soil Sci 123:97-110

Jasper FK, Nilton OR (2009) A comprehensive numerical model of steady state saltation. J Geophys Res. doi:10.1029/2009JD 011702

Liu TS (2009) Loess and arid environment. Anhui Science and Technology Press, Hefei

McKenna Neuman C (2003) Effects of temperature and humidity upon the entrainment of sedimentary particles by wind. Bound Layer Meteorol 31:303-317

McKenna Neuman C, Langston G (2006) Measurements of water content as a control of particle entrainment by wind. Earth Surf Proc Land 31:303-317

McKenna Neuman C, Sanderson S (2008) Humidity control of particle emissions in aeolian systems. J Geophys Res. doi: 10.1029/2007JF000780

McTainsh G, Strong C (2007) The role of aeolian dust in ecosystems. Geomorphology 89:39-54

Qian ZA, Song MH, Li WY (2002) Analyses on distributive variation and forecast of sand-dust storms in recent 50 years in North China. J Desert Res 2:106-111

Ravi S, D’Odorico P (2005) A field-scale analysis of the dependence of wind erosion threshold velocity on air humidity. Geophys Res Lett. doi:10.1029/2005GL023675

Ravi S, D'Odorico P, Over TM et al (2004) On the effect of air humidity on soil susceptibility to wind erosion: the case of air dry soils. Geophys Res Lett. doi:10.1029/2004GL019485

Remigius EO (2003) Wind tunnel study on Aeolian saltation dynamics and mass flow. J Arid Environ 53:569-583

Sankey JB, Germino MJ, Glenn NF (2009) Relationships of post-fire aeolian transport to soil and atmospheric conditions. Aeolian Res $1: 75-85$

Sensit Company (2007) Technical description for the new model H11-LIN. Sensit Company, Portland, pp 13-14

Shao YP (2008) Physics and modelling of wind erosion. Springer, University of Cologne, Germany

Shi F, Huang N (2010) Experiments and numerical simulation for aeolian saltation in natural environments. Dissertation, University of Lanzhou

Stout JE (2003) Seasonal variations of saltation activity on a High Plains Saline Playa: Yellow Lake, Texas. Phys Geogr 1:61-76

Stout JE (2004) A method for establishing the critical threshold for aeolian transport in the field. Earth Surf Proc Land 29:11951207

Stout JE (2007) Simultaneous observations of the critical aeolian threshold of two surfaces. Geomorphology 85:3-16

Stout JE (2010) Diurnal patterns of blowing sand. Earth Surf Process Landf 35:314-318 
Sun JM, Liu TS (2006) The age of the Taklimakan Desert. Science 312:1621. doi: $10.1126 /$ science. 1124616

Van Boxel JH, Arens SM, Van Dijk PM (1999) Aeolian processes across transverse dunes. I: modelling the air flow. Earth Surf Proc Land 24(3):255-270

Van Pelt RS, Zobeck TM, Peters P et al (2006) Wind tunnel testing and comparison of three saltation impact sensors. In: International Conference on Aeolian Research, Guelph, Ontario, Canada

Wang SG, Dong GR, Chen HZ et al (2000) Advances in studying sand-dust storms of China. J Desert Res 4:349-356

Wang X, Ma Y, Chen HW, Tao ZY (2003) Analysis on the climatic characteristics of sandstorms in south Xinjiang. J Desert Res 2:147-151

Wheaton EE, Chakravarti AK (1990) Dust storms in the Canadian Prairies. Int J Climatol 10:829-837
Wiggs GFS, Baird AJ, Atherton RJ (2004) The dynamic effects of moisture on the entrainment and transport of sand by wind. Geomorphology 59:13-30

Yang XH, He Q, Ali M et al (2012) A field experiment on dust emission by wind erosion in the Taklimakan Desert. Acta Meteorol Sin 26(2):241-249

Zhao TL, Gong SL, Zang XY et al (2006) A simulated climatology of Asian dust aerosol and its trans-pacific transport. Part I: mean climate and validation. J Clim 19:88-103

Zheng XJ, Huang N, Zhou YH (2003) Laboratory measurement of electrification of wind-blown sands and simulation of its effect on sand saltation movement. J Geophys Res. doi:10.1029/2002 JD002572

Zhou ZJ, Wang XW, Niu RY (2002) Climate characteristics of sandstorm in China in recent 47 years. J Appl Meteorol Sci $2: 193-200$ 